\title{
Risk and protective factors related to children's symptoms of emotional difficulties and hyperactivity/inattention during the COVID-19-related lockdown in France: results from a community sample
}

\author{
Flore Moulin ${ }^{1,5}\left[\right.$ - Tarik El-Aarbaoui ${ }^{2} \cdot$ Joel José Herranz Bustamante ${ }^{2} \cdot$ Mégane Héron $^{2} \cdot$ Murielle Mary-Krause $^{2}$. \\ Alexandra Rouquette $^{3,4} \cdot$ Cédric Galéra $^{1,5,6} \cdot$ Maria Melchior $^{2}$
}

Received: 19 August 2020 / Accepted: 23 February 2021 / Published online: 9 March 2021

(c) Springer-Verlag GmbH Germany, part of Springer Nature 2021

\begin{abstract}
Objective The COVID-19 epidemic has spread worldwide since December 2019. To contain it, preventive measures including social distancing, economic shutdown, and school closures were introduced, carrying the risk of mental health burden in adults and children. Although the knowledge base regarding children's response to trauma and adverse events in general has broadened, descriptions of their mental health during epidemics remain scarce. In particular, the role of family socioeconomic characteristics and parental mental health are poorly understood.

Methods We assessed the correlates of children's emotional difficulties and symptoms of hyperactivity/inattention during the COVID-19 lockdown in a French community-based sample. Data came from 432 community-based parents (27-46 years, TEMPO cohort) and their children (mean age $6.8 \pm 4.1$ ) interviewed online. Children's symptoms of emotional difficulties and hyperactivity/inattention were assessed using the parent-reported Strengths and Difficulties Questionnaire during the 5 th week of home confinement. Family socioeconomic characteristics and parental mental health and substance use were assessed weekly during the first 5 weeks of home confinement. Data were analyzed using logistic regression models.

Results $7.1 \%$ of children presented symptoms of emotional difficulties and $24.7 \%$ symptoms of hyperactivity/inattention. Family financial difficulties and parental symptoms of anxiety and depression, as well as children's sleeping difficulties and screen time, were associated with the presence of psychological difficulties.

Conclusion Children's emotional and behavioural difficulties are associated with parental mental health and socioeconomic difficulties. In the unprecedented situation of the COVID-19 epidemic, parents and professionals involved in caring for children should pay special attention to their mental health needs.
\end{abstract}

Keywords Children's mental health $\cdot$ Self-report $\cdot$ Epidemiology $\cdot$ Community survey: COVID-19

\section{Introduction}

As the coronavirus (COVID-19) epidemic progresses worldwide, on March 17, 2020, the French Government ordered a nationwide lockdown, with strict social restrictions and limitations of individuals' movements. Families were confined

Cédric Galéra and Maria Melchior co-last author contributed equally.

Flore Moulin

fmoulin.science@gmail.com

1 Bordeaux Population Health Research Center, INSERM U 1219, Bordeaux, France

2 INSERM Sorbonne Université, IPLESP, ERES UMRS 1136, Paris, France
3 Université Paris-Saclay, UVSQ, Inserm, CESP, Paris, France

4 AP-HP, Bicêtre Hospital, Public Health and Epidemiology Department, Le Kremlin-Bicêtre, France

5 Université de Bordeaux, Bordeaux, France

6 Department of Child and Adolescent Psychiatry, Centre Hospitalier Charles Perrens, Bordeaux, France 
to their homes, with the risk of job loss, salary reduction or closure of regular activities such as schools. According to UNESCO, as of April 1st 2020, the infection has caused 194 countrywide closures around the world, thus affecting 1,598,099,000 students, knowing that school closures have been shown to have an impact on children psychological difficulties [1-3], school closure may also cause disruptions in physical activity, social interactions, and mental health of children and adolescents.

Prior studies on the health impact of a quarantine [1, 4, 5] have shown that when children are out of school, they are physically less active, have longer screen time and irregular sleep patterns, resulting in weight gain and loss of cardiorespiratory fitness, which can all subsequently impact their psychological well-being.

There is evidence that in some special populations, such as children of health workers [6], children with a chronic disease [7] as well as those suffering from ADHD before the epidemic [8,9], the COVID-19 outbreak and the accompanying disease containment measures introduced had an impact on psychological well-being. However, though research highlights children's mental health risks associated with anxiety, lack of peer contacts, reduced opportunities for stress regulation or parental mental illness [10-12], and several reports $[1,13,14]$ call for further research, to date there is little epidemiological data on the mental health of children drawn from the community in face of the COVID19 epidemic.

Given the well-known associations between family characteristics such as parental mental health [15-17], low socioeconomic position [17],18] and offspring high risk of poor mental health $[15,16]$, we chose to specifically examine the role of these factors.

\section{The current study}

The aim of our study was to assess family and individual correlates of children's symptoms of emotional difficulties and hyperactivity/inattention in a community-based sample in France.

We assumed that children's characteristics such as sleeping difficulties, elevated screen time use, as well as the family's circumstances including parents' marital situation (single vs living together), financial difficulties, low income and unstable work situation during lockdown, parents' symptoms of anxiety and depression or substance use, and parents' experience of COVID-19 symptoms were correlated to children's psychological difficulties and studied these characteristics.

\section{Methods}

\section{Setting and study design}

Data for this study come from a longitudinal survey of a cohort of parents who took part in the 2020 online assessment of the TEMPO (Trajectoires EpidéMiologiques en Population) COVID-19 study (www.tempo.inserm.fr).

\section{Sample characteristics}

The TEMPO study was set up in 2009 to examine associations between life circumstances and substance use and mental health in young adults. All TEMPO participants have a parent who took part in the GAZEL cohort study $[19,20]$. TEMPO study participants were recruited in 1991 when 2585 children aged 4-16 were selected to take part in a survey of their mental health. In 2009, all 1991 study participants (aged 22-35 at the time) were invited to participate again: 1103 agreed, of whom 752 agreed to a longitudinal follow-up [21]. In 2011, we conducted a new wave of data collection and the study sample was expanded to all GAZEL participants' offspring aged 18-37 years [22] (Fig. 1). The TEMPO study received approval from France's national committees for data protection (CCTIRS: Comité Consultatif sur le Traitement des Informations pour la Recherche en Santé: CNIL: Commission Nationale Informatique et Liberté).

\section{Sample}

On March 17, 2020, 7730 cases of COVID-19 were reported by France's public health authorities, among them 2759 were hospitalized and 700 were in intensive care [23], pushing the French government to order a nationwide lockdown. From March 24th to April 28th 2020, TEMPO participants were invited by email to complete a weekly online questionnaire. The four initial questionnaires focused on sociodemographics, work characteristics, COVID-19 infection, general and mental health, as well as substance use. During the 5th week of lockdown, the questionnaire assessed participants' children's mental health and was completed by 432 participants. Participants who had more than one child were asked to complete the questionnaire in reference to their youngest child. Sample characteristics are described in Table 1. In total, 432 participants, including 276 women $(65 \%)$ and 148 men (34.9\%), completed the study questionnaire about their children: $31(7.2 \%)$ children had signs of emotional difficulties and 107 (24.8\%) of symptoms of hyperactivity/ inattention. 


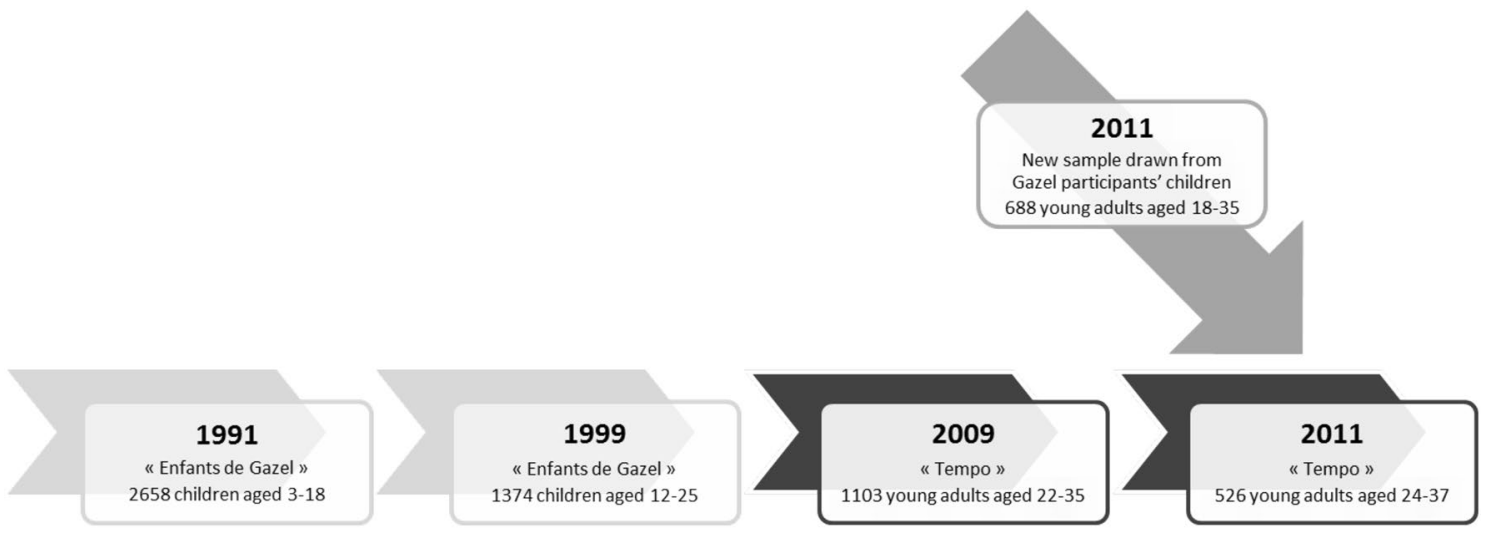

Fig. 1 Design of the cohort study using both TEMPO participants' and GAZEL participants'

\section{Ethical section}

The TEMPO study received approval from France's national committees for data protection (CCTIRS: Comité Consultatif sur le Traitement des Informations pour la Recherche en Santé: CNIL: Commission Nationale Informatique et Liberté).

\section{Measures}

\section{Children}

We used the SDQ to ascertain symptoms of emotional difficulties and hyperactivity/inattention.

Emotional and hyperactivity/inattention symptoms Children's symptoms of emotional difficulties as well as hyperactivity/inattention were reported by parents using the Strengths and Difficulties Questionnaire (SDQ) during the 5th week (from 20 to 26th of April 2020) of home confinement. The SDQ is a brief, 25-item, measure of behavioral and emotional difficulties that can be used in children and young people aged 4-17 years [24-26]. In this study, we used two subscales: "emotional difficulties" and symptoms of "hyperactivity/inattention", with five items each. Each item was scored on a 3 points ordinal Likert scale (0 "not true"; 1 "somewhat true"; 2 "certainly true"). A cut-off of $>3$ out of 10 was used to detect high symptom levels on emotional difficulties scale and of $>5$ out of 10 to detect high symptoms levels on hyperactivity/inattention scale. The internal consistency of the subscales was acceptable (Cronbach's $\alpha$ of 0.62 for emotional difficulties and 0.74 for symptoms of hyperactivity/inattention).

Risk factors of children's psychological difficulties Risk factors studied in this investigation included children's age, sleep and screen time use, family sociodemographic char- acteristics, parents' mental health and substance use, and parents' experience of COVID-19 symptoms.

Children's characteristics (sociodemographics, sleeping difficulties, screen time) The child's sociodemographic characteristics included sex (female vs. male), age ( $>$ or $\leq 6$ years old).

Sleeping difficulties were assessed by the following questions: "During the preceding 7 days, did your child have difficulties sleeping that: appeared or increased or decreased or disappeared or stayed stable or no difficulties." We created the following categories "Sleeping difficulties (including "sleeping difficulties that "appeared" or "increased" or "stayed stable") vs. "No sleeping difficulties" (including "no difficulties", or "difficulties disappeared" or "difficulties decreased").

Screen time was assessed by the following questions: "During the preceding 7 days, how much time has your child spent in front of a screen (TV, tablet, computer, smartphone..) per day. We created the two following categories: "Less than $1 \mathrm{~h}$ ", vs. "More than $1 \mathrm{~h}$ ", based on the American Academy of Pediatrics new Recommendations for Children's Media Use [27].

\section{Parents}

Family sociodemographic characteristics Sociodemographic characteristics studied include: family situation (single vs couple), financial difficulties in the preceding 5 weeks (yes vs no), household monthly income (2500 euro or less vs $>2500$ euro) (in reference to the average income in France) [28] and work situation during lockdown (normal /distance working vs job loss/unemployment vs sick leave).

Parents' mental health To assess parents' symptoms of anxiety and depression during the first 5 weeks of lockdown, we used weekly repeated measures of the subscale assessing 
Table 1 Descriptive characteristics of children of TEMPO 2020 study participants during the COVID-19 lockdown in France $(n=432)$

\begin{tabular}{|c|c|}
\hline Variable & Frequency $(\%$ \\
\hline \multicolumn{2}{|l|}{$S D Q$ scores in the children } \\
\hline \multicolumn{2}{|l|}{ High emotional difficulties } \\
\hline Yes & $31(7.2)$ \\
\hline No & $401(92.8)$ \\
\hline \multicolumn{2}{|l|}{ High hyperactivity/inattention } \\
\hline Yes & $107(24.8)$ \\
\hline No & $325(75.2)$ \\
\hline \multicolumn{2}{|l|}{ Children's characteristics } \\
\hline \multicolumn{2}{|l|}{ Age } \\
\hline$\leq 6$ years & $172(51.5)$ \\
\hline$>6$ years & $162(48.5)$ \\
\hline \multicolumn{2}{|l|}{ Sex } \\
\hline Female & $164(48.9)$ \\
\hline Male & $171(51.0)$ \\
\hline \multicolumn{2}{|l|}{ Sleeping difficulties } \\
\hline Yes & $69(21.2)$ \\
\hline No & $256(78.8)$ \\
\hline \multicolumn{2}{|l|}{ Screen time (per day) } \\
\hline$<1 \mathrm{~h}$ & $88(26.8)$ \\
\hline$>1 \mathrm{~h}$ & $240(73.1)$ \\
\hline \multicolumn{2}{|l|}{ Family sociodemographic characteristics } \\
\hline \multicolumn{2}{|l|}{ Parental situation during COVID-19 lockdown } \\
\hline Single/biological parents not living together & $152(40.2)$ \\
\hline Parental couple living together & $226(59.8)$ \\
\hline \multicolumn{2}{|l|}{ Sex of the responding participant } \\
\hline Female (Yes) & $276(65.0)$ \\
\hline Male & $148(34.9)$ \\
\hline \multicolumn{2}{|l|}{ Number of children in the family } \\
\hline$\leq 2$ & $185(80.8)$ \\
\hline$>2$ & $44(19.2)$ \\
\hline \multicolumn{2}{|l|}{ Financial difficulties } \\
\hline No & $382(89.9)$ \\
\hline Yes & $43(10.1)$ \\
\hline \multicolumn{2}{|l|}{ Average Family Income (/month) } \\
\hline$\leq 2500$ euros $($ Ref $)$ & $148(34.3)$ \\
\hline$>2500$ euros & $284(65.7)$ \\
\hline \multicolumn{2}{|l|}{ Job situation } \\
\hline Normal/distance working & $289(76.0)$ \\
\hline $\begin{array}{l}\text { Unemployment/job loss during confinement/sick } \\
\text { leave }\end{array}$ & $119(29.1)$ \\
\hline \multicolumn{2}{|l|}{ Parental characteristics } \\
\hline \multicolumn{2}{|l|}{ COVID-19 symptoms } \\
\hline Yes & $28(6.5)$ \\
\hline No & $404(93.5)$ \\
\hline \multicolumn{2}{|l|}{ Parental mental health difficulties during lockdown } \\
\hline \multicolumn{2}{|l|}{ Symptoms of anxiety-depression } \\
\hline Yes & $118(27.3)$ \\
\hline No & $314(72.7)$ \\
\hline
\end{tabular}

Table 1 (continued)

\begin{tabular}{lc}
\hline Variable & Frequency $(\%)$ \\
\hline Substance use & \\
Tobacco smoker & \\
Yes & $49(16.8)$ \\
No & $243(83.2)$ \\
Problematic alcohol use & \\
Yes & $31(10.9)$ \\
No & $254(89.1)$ \\
\hline
\end{tabular}

$S D Q$ strength and difficulties questionnaire. Note 1: Frequency and percentages for categorical variables. Note 2: Owing to missing values, the frequencies of some categorical variables do not add up to 432

anxious-depressed symptoms in the Adult Self Report Scale (ASR) [29], creating a dichotomized T-score with a cut-off based on +1 standard deviation from the mean. Additionally, using an assessment of ASR-based anxious-depressed symptoms obtained in the TEMPO study in 2018, we also identified parents' symptoms of anxiety and depression before lockdown, which were studied in additional analyses.

Parents' substance use Participants reported levels of substance use and abuse during the first 5 weeks of lockdown in weekly questionnaires.

Tobacco smoking status was assessed using the following question in week 1: "Are you a regular or occasional smoker?" coded yes vs. no.

Alcohol use was assessed using the French version of the Alcohol Use Disorders Identification Test (AUDIT-C) [30, 31]. This brief three-item alcohol screening tool developed by the WHO focuses on the frequency and quantity of alcohol consumption [32], matches DSM IV criteria for alcohol abuse and dependence and is validated against clinical diagnosis. Audit-C test scores of 3 or more for women and 4 or more for men were considered to indicate a heightened risk for hazardous drinking/alcohol use disorder [32, 33].

COVID-19 symptoms of the parents Parents' COVID-19 symptoms during the first 5 weeks were ascertained weekly by the following question: "Did you present symptoms of COVID-19 infection (fever, cough, loss of taste or smell)"? Based on participants' weekly repeated responses ("yes" vs "no"), we created a variable indicating the presence of symptoms prior to the measure of children's psychological difficulties.

\section{Statistical analyses}

First, descriptive statistics including frequencies and percentages were used to characterize the study population (Table 1). We tested bivariate associations between potential 
individuals and family risk factors, and children's symptoms of emotional difficulties or hyperactivity/inattention using the Chi-square test (Tables 2 and 3).

Second, to identify factors associated with children's emotional difficulties and symptoms of hyperactivity/inattention, we used logistic regression with the alpha value set at $P<0.05$. We built one model, adjusting for the child's age and sex, and an additional multivariate model adjusting for all variables that were significantly associated with the study outcomes in bivariate analyses.

\section{Additional analyses}

We tested for statistical interactions between children's age and sex on one hand and parents' mental health and financial difficulties on the other. None of these statistical interactions were statistically significant.

All statistical analyses were conducted using STATA 16.1 (StataCorp, College Station, Texas, USA).

\section{Results}

\section{Sample characteristics (Table 1)}

Sample characteristics are described in Table 1. In total, 432 participants, including 276 women $(65 \%)$ and 148 men (34.9\%), completed the study questionnaire about their children: 31 (7.2\%) children had signs of emotional difficulties and $107(24.8 \%)$ of symptoms of hyperactivity/inattention.

Tables 2 and 3 show factors associated with children's emotional difficulties and symptoms of hyperactivity/ inattention.

\section{Risk factors of children's emotional difficulties and symptoms of hyperactivity/inattention (Tables 2, 3)}

\section{Emotional symptoms}

Age- and sex-adjusted logistic regression analyses (Table 2) showed that the odds of children's high levels of emotional difficulties were elevated among those who had sleeping difficulties (OR 2.6, 95\% CI 1.2-5.7), whose screen time was more than $1 \mathrm{~h}$ per day (OR 6.8, 95\% CI 1.5-30.9), whose parents had symptoms of anxiety-depression during lockdown (OR 8.1, 95\% CI 2.4-26.8), or who had financial difficulties (OR 4.2, 95\% CI 1.6-11.0).

Family situation (OR 1.2, 95\% 0.6-2.7), the number of children in the family (OR 1.0, 95\% 0.3-3.2), income (OR $1.1,95 \% 0.5-2.4$ ), job situation (OR 1.6, 95\% 0.7-3.5), COVID-19 symptoms (OR 1.7, 95\% 0.5-5.3), and parents' substance use, such as tobacco consumption (OR 2.3, 95\%
0.8-6.6) and problematic alcohol consumption (OR 0.7, 95\% 0.1-3.8) were not associated with children's high levels of emotional difficulties.

These associations did not change in a multivariate regression models, except for sleep difficulties and financial difficulties, which were no longer associated with children's emotional symptoms.

\section{Symptoms of hyperactivity/inattention}

Age- and sex-adjusted logistic regression analyses (Table 3) showed that the odds of children's symptoms of hyperactivity/inattention were elevated among children who had sleeping difficulties (OR 2.0, 95\% CI 1.1-3.3), had parents with symptoms of anxiety or depression (OR 2.6, 95\% CI 1.1-1.2), financial difficulties (OR 2.3, 95\% CI 1.1-4.6), or who were unemployed (OR 1.8, 95\% CI 1.1-3.3).

The child's screen time (OR 1.3, 95\% CI 0.9-1.9), the responding parent's sex (OR $0.7,95 \%$ CI $0.4-1.2$ ), the family situation (OR 1.4, 95\% CI 0.9-2.3), the number of children in the family (OR $0.6,95 \%$ CI $0.3-1.5$ ), parents' substance use such as tobacco consumption (OR 0.8, 95\% 0.4-1.6) and problematic alcohol consumption (OR 1.2, 95\% 0.7-1.9), COVID symptoms (OR 0.9, 95\% CI 0.4-2.1), or income (OR 1.0, 95\% CI 0.6-1.7) were not associated with children's elevated levels of symptoms of hyperactivity/ inattention.

These associations did not change in a multivariate regression model, except for sleeping difficulties and parental work situation, which were no longer associated with children's symptoms of hyperactivity/inattention.

\section{Discussion}

\section{Main findings}

Ours is one of the first studies to explore children's psychological symptoms and their correlates during the COVID-19 epidemic and associated lockdown. Overall, when adjusting on age and sex, children's emotional difficulties and symptoms of hyperactivity/inattention were significantly associated with their sleeping difficulties and screen time exposure, their parents' symptoms of anxiety or depression and financial difficulties. Parental employment situation was associated with children's symptoms of hyperactivity/ inattention only, in an age- and sex-adjusted model. Overall, children's symptoms of frequent psychological difficulties are associated with known risk factors of youth mental health problems. Children of parents who have psychological difficulties or who experience socioeconomic difficulties should benefit from special attention from primary and mental health practitioners. 
Table 2 Parental characteristics and children's psychological emotional difficulties during COVID-19 lockdown in France (TEMPO COVID-19 Questionnaire 2020, age- and sex-adjusted odds ratios, multivariate model, Chi Square tests)

\begin{tabular}{|c|c|c|c|c|c|c|c|}
\hline \multicolumn{8}{|l|}{ Emotional symptoms } \\
\hline Characteristics $^{\mathrm{a}}$ & Yes & No & $\mathrm{Chi}^{2}$ test & $\begin{array}{l}\text { Age- and } \\
\text { sex-adjusted } \\
\text { OR }\end{array}$ & $95 \%$ Wald CI & $\begin{array}{l}\text { Multivari- } \\
\text { ate model } \\
\mathrm{OR}^{\mathrm{c}}\end{array}$ & $95 \%$ Wald CI \\
\hline \multicolumn{8}{|l|}{ Children's characteristics } \\
\hline Age & & & 0.3 & 1.5 & $0.7-3.2$ & 1.1 & $0.4-2.6$ \\
\hline$\leq 6$ years old & $13(41.9)$ & $159(52.4)$ & & & & & \\
\hline$>6$ years old & $18(58.0)$ & $144(47.5)$ & & & & & \\
\hline Sex & & & 0.2 & 1.0 & $0.9-1.1$ & 1.8 & $0.7-4.1$ \\
\hline Female & $18(58.0)$ & $146(48.0)$ & & & & & \\
\hline Male (Ref) & 13 (41.9) & $158(51.9)$ & & & & & \\
\hline Sleeping difficulties & & & $<0.05$ & $2.6^{\mathrm{b}}$ & $1.2-5.7$ & 2.0 & $0.8-4.8$ \\
\hline No (Ref) & $19(61.3)$ & $237(80.6)$ & & & & & \\
\hline Yes & $12(38.7)$ & $57(19.3)$ & & & & & \\
\hline Screen time per day & & & $<0.05$ & $6.8^{\mathrm{b}}$ & $1.5-30.9$ & $6.2^{\mathrm{b}}$ & $1.4-28.0$ \\
\hline$<1 \mathrm{~h}(\mathrm{Ref})$ & $2(6.4)$ & $86(28.9)$ & & & & & \\
\hline$>1 \mathrm{~h}$ & $29(93.5)$ & $211(71.0)$ & & & & & \\
\hline \multicolumn{8}{|c|}{ Family sociodemographic characteristics during lockdown } \\
\hline Family situation & & & 0.8 & 1.2 & $0.6-2.7$ & 0.7 & $0.3-1.9$ \\
\hline Single/biological parents not living together & $12(41.4)$ & $140(40.1)$ & & & & & \\
\hline Couple & $17(58.6)$ & $209(59.9)$ & & & & & \\
\hline Sex of the responding parent during the 5 week & & & $<0.05$ & 2.5 & $0.9-6.8$ & 1.7 & $0.6-6.1$ \\
\hline Female & $26(83.9)$ & $250(63.6)$ & & & & & \\
\hline Male (Ref) & $5(16.1)$ & $140(36.4)$ & & & & & \\
\hline Number of children in the family & & & 0.8 & 1.0 & $0.3-3.2$ & 0.9 & $0.3-3.1$ \\
\hline$\leq 2$ & $18(81.8)$ & $167(80.7)$ & & & & & \\
\hline$>2$ & $4(18.1)$ & $40(19.3)$ & & & & & \\
\hline Financial difficulties & & & $<0.05$ & $4.2^{\mathrm{b}}$ & $1.6-11.0$ & 2.3 & $0.8-6.2$ \\
\hline No (Ref) & $22(73.3)$ & $360(91.4)$ & & & & & \\
\hline Yes & $8(26.7)$ & $355(8.9)$ & & & & & \\
\hline Income & & & 0.8 & 1.1 & $0.5-2.4$ & 0.9 & $0.4-2.1$ \\
\hline 2500 euros or less (Ref) & $30(28.0)$ & $118(36.3)$ & & & & & \\
\hline$>2500$ euros & $77(71.9)$ & $207(63.7)$ & & & & & \\
\hline Job situation & & & 0.2 & 1.6 & $0.7-3.5$ & 1.3 & $0.5-3.2$ \\
\hline Normal activity/teleworking & $17(68)$ & $272(76.6)$ & & & & & \\
\hline $\begin{array}{l}\text { Unemployment/job loss during confinement/Sick } \\
\text { leave }\end{array}$ & $11(39.2)$ & $108(28.4)$ & & & & & \\
\hline \multicolumn{8}{|l|}{ Parental characteristics during lockdown } \\
\hline COVID-19 symptoms (during lockdown) & & & 0.3 & 1.7 & $0.5-5.3$ & 2.2 & $0.6-10.0$ \\
\hline Yes & $4(11.4)$ & $27(6.9)$ & & & & & \\
\hline No & $31(88.6)$ & $369(93.1)$ & & & & & \\
\hline \multicolumn{8}{|l|}{ Parental mental health } \\
\hline $\begin{array}{l}\text { Symptoms of anxiety-depression during lock- } \\
\text { down }\end{array}$ & & & $<0.05$ & $8.1^{\mathrm{b}}$ & $2.4-26.8$ & $5.7^{\mathrm{b}}$ & $2.4-5.1$ \\
\hline No (Ref) & $8(50)$ & $133(84.1)$ & & & & & \\
\hline Yes & $8(50)$ & $25(15.8)$ & & & & & \\
\hline \multicolumn{8}{|l|}{ Parents' substance use } \\
\hline Tobacco (regular smoker $>$ 10/day) & & & 0.06 & 2.3 & $0.8-6.6$ & 1.4 & $0.4-5.4$ \\
\hline Yes & $10(58.8)$ & $73(36.3)$ & & & & & \\
\hline No & 7 (41.2) & $128(63.7)$ & & & & & \\
\hline
\end{tabular}


Table 2 (continued)

\begin{tabular}{|c|c|c|c|c|c|c|c|}
\hline \multicolumn{8}{|l|}{ Emotional symptoms } \\
\hline Characteristics $^{\mathrm{a}}$ & Yes & No & $\mathrm{Chi}^{2}$ test & $\begin{array}{l}\text { Age- and } \\
\text { sex-adjusted } \\
\text { OR }\end{array}$ & $95 \%$ Wald CI & $\begin{array}{l}\text { Multivari- } \\
\text { ate model } \\
\mathrm{OR}^{\mathrm{c}}\end{array}$ & $95 \%$ Wald CI \\
\hline Problematic consumption of alcohol & & & 0.8 & 0.7 & $0.1-3.8$ & 0.4 & $0.07-2.8$ \\
\hline Yes & $2(9.5)$ & $29(11)$ & & & & & \\
\hline No & $19(90.5)$ & $235(89.0)$ & & & & & \\
\hline
\end{tabular}

Note. TEMPO Trajectoires Epidémiologiques en Population; $C I$ confidence interval; $O R$ odds ratio

${ }^{a}$ Owing to missing values, the frequencies of some categorical variables do not add up to 432

${ }^{\mathrm{b}}$ Statistically significant $(P<0.05)$

${ }^{\mathrm{c}}$ Multivariate model: age- and sex-adjusted analysis, additionally adjusted on all variables that were significant in bivariate analysis $(P<0.05)$ : sleeping difficulties, screen time, sex of the responding parent, financial difficulties, symptoms of anxiety-depression during lockdown

\section{Interpretation of study findings}

We discuss our findings on the role of parents' mental health and socioeconomic characteristics on the one side, and children's sleep disorders and screen time use on the other side.

\section{Parents' characteristics}

In accordance with previous research [34-36], parents' symptoms of anxiety or depression during lockdown, as well as parents' pre-existing mental health difficulties, were associated with a higher level of children's emotional difficulties and symptoms of hyperactivity/inattention.

In a stressful period such as the COVID-19 epidemic and resulting disruptions of daily life, parents are the best resource for children to seek help from. Good parenting skills are hence crucial when children are confined at home [1]. In general, children with a mentally ill parent more frequently experience negative emotions, including anger, fear, and sadness. They also show higher levels of disturbed attachment and difficulties in emotional regulation [37]. Consequently, they are at elevated risk of internalizing problems, such as depression and anxiety $[15,16]$.

Concerning children's symptoms of hyperactivity/inattention, the study of Zhang [9] showed that they were related to parent's mood during the COVID-19 outbreak in China. Additionally, parents of children with ADHD experience high levels of daily child-rearing stressors [38, 39], therefore, this association may also be bidirectional. The special combination of school closures and children staying at home might bring elevated difficulties and stress for both children and their parents. Our results have significant clinical implications concerning the importance of assessing parents' negative mood when evaluating children's well-being. During periods of lockdown, when assessing a child, mental health practitioners should pay further attention to the mental health status of the parents, especially looking for depression or anxiety symptoms.

Similarly, independently of home confinement, previous research has reported that children of parents with substance use disorders, [40-42], have an elevated likelihood of additional mental disorders. However, we found no relationship between parental consumption of tobacco or alcohol and offspring psychological difficulties. This may reflect low rates of tobacco and alcohol use among TEMPO cohort participants [43].

In our study, having a parent who presented with symptoms of COVID-19 was not associated with a higher score of emotional difficulties or hyperactivity/inattention. In a recent Chinese study [34], having relatives or acquaintances infected with COVID-19 was an independent risk factor of anxiety among college students, probably due to the high contagiousness of the illness [44]. It is important to note that parental COVID-19 symptoms were selfreported since biological testing was hardly available during the lockdown. It may also be that individuals who were too ill were not able to respond to TEMPO study questionnaires.

Parental financial difficulties and work situation were associated with children's emotional difficulties and symptoms of hyperactivity/inattention. Stability of family income has been found to be significantly associated with youth anxiety during the COVID 19 crisis, due to links with psychological and economic pressure $[34,45]$.

Our findings indicate an increased risk of psychological difficulties in children whose family had psychological or financial difficulties during lockdown. This result is consistent with previous studies, which demonstrated that parents with financial difficulties are at higher risk of mental health difficulties such as anxiety. Economic decline [46] is associated with increased mental health problems for youths that may be affected by its consequences on adult unemployment and mental health, such as depression [14, 47]. 
Table 3 Parental characteristics and children's symptoms of hyperactivity/inattention during the COVID-19 lockdown in France (TEMPO Covi19 Questionnaire 202O, age- and sex-adjusted odds ratios, multivariate model, Chi Square tests)

\begin{tabular}{|c|c|c|c|c|c|c|c|}
\hline \multicolumn{8}{|l|}{ Hyperactivity/inattention symptoms } \\
\hline Characteristics $^{\mathrm{a}}$ & Yes & No & $\mathrm{Chi}^{2}$ test $P$-value & $\begin{array}{l}\text { Age and } \\
\text { sex-adjusted } \\
\text { OR }\end{array}$ & $95 \%$ Wald CI & $\begin{array}{l}\text { Multivari- } \\
\text { ate model } \\
\mathrm{OR}^{\mathbf{c}}\end{array}$ & $95 \%$ Wald CI \\
\hline \multicolumn{8}{|l|}{ Children characteristics } \\
\hline Age & & & 0.4 & 0.9 & $0.9-1.0$ & 1.1 & $0.6-1.9$ \\
\hline$\leq 6$ years old $(\operatorname{Ref})$ & $51(48.1)$ & $121(53.1)$ & & & & & \\
\hline$>6$ years old & $55(51.9)$ & $107(46.9)$ & & & & & \\
\hline Sex & & & & 0.7 & $0.4-1.1$ & 0.7 & $0.4-1.1$ \\
\hline Female & $46(42.9)$ & $118(51.7)$ & 0.7 & & & & \\
\hline Male (Ref) & $61(57.1)$ & $110(48.2)$ & & & & & \\
\hline Sleeping difficulties & & & $<0.05$ & $2.0^{\mathrm{b}}$ & $1.1-3.3$ & 1.7 & $0.9-3.0$ \\
\hline No (Ref) & $75(70.7)$ & $181(82.6)$ & & & & & \\
\hline Yes & $31(29.2)$ & $38(17.3)$ & & & & & \\
\hline Screen time per day & & & 0.07 & 1.3 & $0.9-1.9$ & 1.5 & $0.8-2.8$ \\
\hline$<1 \mathrm{~h}(\mathrm{Ref})$ & $22(20.5)$ & $66(29.8)$ & & & & & \\
\hline$>1 \mathrm{~h}$ & $85(79.4)$ & $155(70.1)$ & & & & & \\
\hline \multicolumn{8}{|c|}{ Family sociodemographic characteristics during lockdown } \\
\hline Family situation & & & 0.6 & 1.4 & $0.9-2.3$ & 1.3 & $0.7-2.1$ \\
\hline $\begin{array}{l}\text { Single/biological parents not living } \\
\text { together }\end{array}$ & $42(42.4)$ & $110(39.4)$ & & & & & \\
\hline Couple (Ref) & $57(57.6)$ & $169(60.6)$ & & & & & \\
\hline Sex of the responding parent & & & 0.8 & 0.7 & $0.4-1.2$ & 0.6 & $0.3-0.9$ \\
\hline Female (Ref) & $68(64.1)$ & $208(65.4)$ & & & & & \\
\hline Male & $38(35.8)$ & $110(34.6)$ & & & & & \\
\hline Number of children in the family & & & 0.3 & 0.6 & $0.3-1.5$ & 0.6 & $0.2-1.4$ \\
\hline$\leq 2$ & $57(85.0)$ & $128(79.0)$ & & & & & \\
\hline$>2$ & $10(14.9)$ & $34(20.9)$ & & & & & \\
\hline Financial difficulties & & & $<0.05$ & $2.3^{\mathrm{b}}$ & $1.1-4.6$ & $4.3^{\mathrm{b}}$ & $1.1-17.9$ \\
\hline No (Ref) & $86(81.9)$ & $296(92.5)$ & & & & & \\
\hline Yes & $19(18.1)$ & $24(7.5)$ & & & & & \\
\hline Income & & & 0.1 & 1.0 & $0.6-1.7$ & 1.0 & $0.6-1.8$ \\
\hline 2500 euros or less (Ref) & $30(28.0)$ & $118(36.3)$ & & & & & \\
\hline$>2500$ euros & 77 (71.9) & $207(63.7)$ & & & & & \\
\hline Job situation & & & 0.1 & $1.8^{\mathrm{b}}$ & $1.1-3.3$ & 1.7 & $1.0-2.9$ \\
\hline Normal activity/teleworking & $67(64.4)$ & $222(73.0)$ & & & & & \\
\hline $\begin{array}{l}\text { Unemployment/job loss during confine- } \\
\text { ment/sick leave }\end{array}$ & $37(35.6)$ & $82(26.9)$ & & & & & \\
\hline \multicolumn{8}{|l|}{ Parental characteristics during lockdown } \\
\hline COVID symptoms for parents & & & 0.8 & 0.9 & $0.4-2.1$ & 0.9 & $0.3-2.4$ \\
\hline Yes & $9(8.5)$ & $26(8.0)$ & & & & & \\
\hline No & $97(91.5)$ & $299(92.0)$ & & & & & \\
\hline \multicolumn{8}{|l|}{ Parental mental health } \\
\hline $\begin{array}{l}\text { Anxious-depressive symptoms during the } \\
\text { first } 5 \text { weeks of lockdown }\end{array}$ & & & 0.1 & $2.6^{\mathrm{b}}$ & $1.0-7.1$ & $2.5^{\mathrm{b}}$ & $1.4-4.2$ \\
\hline No (Ref) & $35(74.5)$ & $106(83.5)$ & & & & & \\
\hline Yes & $12(25.5)$ & $21(16.5)$ & & & & & \\
\hline \multicolumn{8}{|l|}{ Drugs consumption for the parents } \\
\hline Tobacco (regular smoker $>10$ /day) & & & 0.9 & 0.8 & $0.4-1.6$ & 1.6 & $0.6-3.6$ \\
\hline Yes & $19(38)$ & $64(38.1)$ & & & & & \\
\hline No (Ref) & $31(62)$ & $104(61.9)$ & & & & & \\
\hline
\end{tabular}


Table 3 (continued)

\begin{tabular}{lllllll}
\hline Hyperactivity/inattention symptoms & & & & & \\
\hline Characteristics $^{\mathrm{a}}$ & Yes & No & Chi $^{2}$ test $P$-value & $\begin{array}{l}\text { Age and } \\
\text { sex-adjusted } \\
\text { OR }\end{array}$ & $\begin{array}{c}95 \% \text { Wald CI } \\
\begin{array}{l}\text { Multivari- } \\
\text { ate model } \\
\text { OR }^{\mathbf{c}}\end{array}\end{array}$ \\
\hline $\begin{array}{l}\text { Problematic consumption of alcohol since } \\
\text { beginning of home confinement }\end{array}$ & & & 0.06 & 1.2 & $0.7-1.9$ & 0.8 \\
$\begin{array}{l}\text { Yes } \\
\text { No (Ref) }\end{array}$ & $21(23.3)$ & $50(18.2)$ & & & \\
\hline
\end{tabular}

Note. TEMPO Trajectoires Epidémiologiques en Population; $C I$ confidence interval; $O R$ odds ratio

${ }^{a}$ Owing to missing values, the frequencies of some categorical variables do not add up to 432

${ }^{\mathrm{b}}$ Statistically significant $(P<0.05)$

${ }^{\mathbf{c}}$ Multivariate model: age- and sex-adjusted analysis, additionally adjusted on all variables that were significant in bivariate analysis $(P<0.05)$ : sleeping difficulties, financial difficulties, job situation, symptoms of anxiety-depression during lockdown

\section{Children's characteristics}

Children's elevated levels of emotional difficulties and symptoms of hyperactivity/inattention were associated with sleeping difficulties. Because both were measured simultaneously, it is possible that these relationships are bidirectional. Children who are anxious or experience symptoms of depression frequently have sleeping problems, which sometimes appear as a key symptom of distress $[18,48]$. Symptoms of hyperactivity and inattention are core symptoms of ADHD. Similarly, ADHD may disrupt sleep by increasing the probability of bedtime struggles or resistance, limit-setting sleep problems, inadequate sleep hygiene, and insufficient sleep disorder or poor sleep quality. In turn, sleep problems may result in ADHD-like day-time behaviors [49].

In the specific context of COVID-19, Zhang et al. [9] showed that children who have ADHD and experience low overall mood are most likely to see their symptoms of ADHD, including sleep patterns, worsen. Another study [13] found that poor sleep, including nightmares, is among the most frequently reported children's conditions during the COVID-19 outbreak.

In our study, children with emotional difficulties or symptoms of hyperactivity/inattention spent more time in front of a screen during the COVID-19 outbreak than children without such symptoms, which is line with previous studies showing that increased screen time may exacerbate risk for depression, anxiety, suicide, and inattention among children and adolescents [50]. Excessive screen time may also be associated with health risks including poor sleep and sedentarity, which further exacerbate risk of children's psychological difficulties [51, 52]. It is, however, important to note that our study being cross-sectional, screen use may also be a consequence of children's psychological difficulties, both potentially reinforcing one another. Kiraly et al. [53] made some practical guidance to prevent children's problematic
Internet use and emphasize that monitoring and regulating screen time is crucial and can be implemented by involving young people in rule-making [54].

Paradoxically, during the COVID-19 pandemic, many mental health educational resources and support services were offered via online platforms, which required screen use. Obviously, screen time may become over-present during periods of school closure [51], and existing guidelines need to be adequately updated to remain relevant. A recent literature review emphasized that not all screen time is equale.g. doing online lessons for school is different from social media use, which is different from video games [55].

\section{Strengths and limitations}

Our study's main strengths are that it was conducted in the community and started prior to the COVID-19 epidemic, making it possible to control for pre-existing risk factors. However, it also has some limitations that need to be highlighted. First, all measures were based on selfreports, including the children's SDQ scores, which could have been influenced by parental emotional state [56]. Still, parental evaluations are appropriate given the young mean age of surveyed children (i.e. 6 years). Importantly, the performance and validity of the parent-reported SDQ in French [26] suggests that it is a good approximation of a psychiatric interview, in studies of population representative samples [57-59]. Second, we did not assess children's emotional difficulties and hyperactivity/inattention before the COVID-19 epidemic, so we have no information concerning pre-existing vulnerabilities. Children who experienced psychological difficulties prior to the pandemic or had pre-existing mental health problems are at high risk of having symptoms of anxiety [60]. Third, though some variables were assessed longitudinally on a weekly basis during lockdown, the causal relationship between children's and 
parents' characteristics and children's emotional difficulties or symptoms of hyperactivity/inattention cannot be confirmed as children's symptoms were assessed only once. A recent study [61] outlined the need for longitudinal mental health research with children during and after lockdown. Fourth, the relatively small sample of the study limited the statistical power of some analyses. This suggests that a larger sample may show evidence of other risk factors of children's psychological difficulties. Fifth, participants were more likely to live with a partner, have higher education and hold a managerial position than middle-aged adults of the same age in France. Reassuringly, we observed a similar rate of lifetime unemployment compared to the general population [17, 62]. Overall, associations between parental mental health and socioeconomic characteristics, as well as children's sleep and screen use, may actually be stronger than we report. Sixth, children's age range was limited, as the study did not include many very young or adolescent children. However, a focus on pre-teenagers made it possible for us to study a coherent demographic group. Seventh, our measure of children's emotional and behavioural difficulties was dichotomized, which may have limited the statistical power of our analyses, however, we used a validated cutoff, and were thus able to identify children with potentially clinically relevant psychological difficulties.

\section{Implications}

The aim of our study was to assess family and individual risk factors of children's symptoms of emotional difficulties and hyperactivity/inattention in a community-based sample in France.

While the COVID-19 pandemic is spreading all over the world, attention is mostly focused on adults, hiding the public mental health burden in children. Our results underline the necessity to consider long-term mental health effects on this worldwide situation on children, who account for $42 \%$ of the world's population [63].

Risk factors of children's mental health difficulties identified in our study, which have previously been reported, may require special monitoring during the time of the pandemic. For instance, paying attention to sleep difficulties and nightmares, and suggesting sleep hygiene and relaxation methods, could be especially worthwhile during the epidemic [13]. Moreover, screen time guidelines need to updated, as many children and adolescents will not attend school.

Further longitudinal studies should be conducted to test prospective risk factors of children's mental health difficulties. Indeed, even as restrictions are lifted and schools reopen, the psychological impact of the pandemic will last. Increased awareness of the risk factors of mental health difficulties in children in this unprecedented event is needed to prevent them in the short and long terms.
Acknowledgements We thank TEMPO and GAZEL study participants who provided data for this project.

Funding The TEMPO cohort received funding from the French National Research Agency (ANR) including the Flash COVID-19 funding scheme; the French Institute for Public Health Research-IReSP (TGIR Cohortes); the French Inter-departmental Mission for the Fight against Drugs and Drug Addiction (MILDeCA); the French Institute of Cancer (INCa); and the Pfizer Foundation.

Availability of data and materials Upon request.

Code availability STATA 16.1 (StataCorp, College Station, Texas, USA).

\section{Declarations}

Conflict of interest The authors declare that they have no conflicts of interest.

Ethics approval The TEMPO study received approval from France's national committees for data protection (CCTIRS: Comité Consultatif sur le Traitement des Informations pour la Recherche en Santé: CNIL: Commission Nationale Informatique et Liberté).

\section{References}

1. Wang G, Zhang Y, Zhao J et al (2020) Mitigate the effects of home confinement on children during the COVID-19 outbreak. Lancet 395:945-947. https://doi.org/10.1016/S0140-6736(20)30547-X

2. Tang S, Xiang M, Cheung T, Xiang Y-T (2021) Mental health and its correlates among children and adolescents during COVID-19 school closure: the importance of parent-child discussion. J Affect Disord 279:353-360. https://doi.org/10.1016/j.jad.2020.10.016

3. Viner RM, Russell SJ, Croker $\mathrm{H}$ et al (2020) School closure and management practices during coronavirus outbreaks including COVID-19: a rapid systematic review. Lancet Child Adolesc Health 4:397-404. https://doi.org/10.1016/S2352-4642(20)30095 $-\mathrm{X}$

4. Brazendale K, Beets MW, Weaver RG et al (2017) Understanding differences between summer vs school obesogenic behaviors of children: the structured days hypothesis. Int J Behav Nutr Phys Act 14:100. https://doi.org/10.1186/s12966-017-0555-2

5. Mahajan C, Kapoor I, Prabhakar H (2020) Psychological effects of corona virus disease (COVID 19) on children of health care workers. Anesth Analg. https://doi.org/10.1213/ANE.0000000000 005034

6. Brooks SK, Webster RK, Smith LE et al (2020) The psychological impact of quarantine and how to reduce it: rapid review of the evidence. Lancet 395:912-920. https://doi.org/10.1016/S0140 $-6736(20) 30460-8$

7. Martinelli M, Strisciuglio C, Fedele F et al (2020) Clinical and psychological issues in children with inflammatory bowel disease during COVID-19 pandemic. Inflamm Bowel Dis. https:// doi.org/10.1093/ibd/izaa136

8. Bobo E, Lin L, Acquaviva E et al (2020) How do children and adolescents with attention deficit hyperactivity disorder (ADHD) experience lockdown during the COVID-19 outbreak? Encephale. https://doi.org/10.1016/j.encep.2020.05.011

9. Zhang J, Shuai L, Yu H et al (2020) Acute stress, behavioural symptoms and mood states among school-age children with attention-deficit/hyperactive disorder during the COVID-19 
outbreak. Asian J Psychiatr 51:102077. https://doi.org/10.1016/j. ajp.2020.102077

10. Fegert JM, Vitiello B, Plener PL, Clemens V (2020) Challenges and burden of the coronavirus 2019 (COVID-19) pandemic for child and adolescent mental health: a narrative review to highlight clinical and research needs in the acute phase and the long return to normality. Child Adolesc Psychiatry Ment Health 14:20. https ://doi.org/10.1186/s13034-020-00329-3

11. Xie X, Xue Q, Zhou Y et al (2020) Mental health status among children in home confinement during the coronavirus disease 2019 outbreak in Hubei Province, China. JAMA Pediatr. https://doi. org/10.1001/jamapediatrics.2020.1619

12. Liang L, Ren H, Cao R et al (2020) The effect of COVID-19 on youth mental health. Psychiatr Q 91:841-852. https://doi. org/10.1007/s11126-020-09744-3

13. Jiao WY, Wang LN, Liu J et al (2020) Behavioral and emotional disorders in children during the COVID-19 epidemic. J Pediatr 221:264-266.e1. https://doi.org/10.1016/j.jpeds.2020.03.013

14. Golberstein E, Wen H, Miller BF (2020) Coronavirus disease 2019 (COVID-19) and mental health for children and adolescents. JAMA Pediatr. https://doi.org/10.1001/jamapediatrics.2020.1456

15. Merikangas KR, Dierker LC, Szatmari P (1998) Psychopathology among offspring of parents with substance abuse and/or anxiety disorders: a high-risk study. J Child Psychol Psychiatry 39:711-720

16. Weissman MM, Wickramaratne P, Gameroff MJ et al (2016) Offspring of depressed parents: 30 years later. Am J Psychiatry 173:1024-1032. https://doi.org/10.1176/appi.ajp.2016.15101327

17. Melchior M, Chastang J-F, Walburg V et al (2010) Family income and youths' symptoms of depression and anxiety: a longitudinal study of the French GAZEL Youth cohort. Depress Anxiety 27:1095-1103. https://doi.org/10.1002/da.20761

18. Yap MBH, Jorm AF (2015) Parental factors associated with childhood anxiety, depression, and internalizing problems: a systematic review and meta-analysis. J Affect Disord 175:424-440. https:// doi.org/10.1016/j.jad.2015.01.050

19. Redonnet B, Chollet A, Fombonne E et al (2012) Tobacco, alcohol, cannabis and other illegal drug use among young adults: the socioeconomic context. Drug Alcohol Depend 121:231-239. https ://doi.org/10.1016/j.drugalcdep.2011.09.002

20. Lemogne C, Consoli SM, Geoffroy-Perez B et al (2013) Personality and the risk of cancer: a 16-year follow-up study of the GAZEL cohort. Psychosom Med 75:262-271. https://doi.org/10.1097/ PSY.0b013e31828b5366

21. Fombonne E, Vermeersch S (1997) Les enfants de la cohorte GAZEL: I-Prévalence des contacts avec le système médico-éducatif pour des motifs psychologiques, et facteurs associés. Revue d'épidémiologie et de santé

22. Melchior M, Chollet A, Elidemir G et al (2015) Unemployment and substance use in young adults: does educational attainment modify the association? Eur Addict Res 21:115-123. https://doi. org $/ 10.1159 / 000365887$

23. Agence nationale de santé publique". www.santepubliquefrance. fr

24. Goodman R (2001) Psychometric properties of the strengths and difficulties questionnaire. J Am Acad Child Adolesc Psychiatry 40:1337-1345

25. Goodman A, Goodman R (2009) Strengths and difficulties questionnaire as a dimensional measure of child mental health. J Am Acad Child Adolesc Psychiatry 48:400-403. https://doi. org/10.1097/CHI.0b013e3181985068

26. Shojaei T, Wazana A, Pitrou I, Kovess V (2009) The strengths and difficulties questionnaire: validation study in French schoolaged children and cross-cultural comparisons. Soc Psychiatry Psychiatr Epidemiol 44:740-747. https://doi.org/10.1007/s0012 7-008-0489-8
27. American Academy of Pediatrics Announces New Recommendations for Children's Media Use. APA.org

28. INSEE: Revenu disponible par ménage (moyenne et médiane). http://www.insee.fr/fr/themes/tableauasp?reg_id=0\&ref_ id=NATSOS04202

29. Kessler RC, Adler L, Ames M et al (2005) The World Health Organization adult ADHD self-report scale (ASRS): a short screening scale for use in the general population. Psychol Med 35:245-256. https://doi.org/10.1017/S0033291704002892

30. Reinert DF, Allen JP (2002) The Alcohol Use Disorders Identification Test (AUDIT): A review of recent research. Alcoholism: Clinical and Experimental Research 26:272-279

31. Gache P, Michaud P, Landry U et al (2005) The alcohol use disorders identification test (AUDIT) as a screening tool for excessive drinking in primary care: reliability and validity of a French version. Alcohol Clin Exp Res 29:2001-2007. https:// doi.org/10.1097/01.alc.0000187034.58955.64

32. Bohn MJ, Babor TF, Kranzler HR (1995) The alcohol-use disorders identification test (audit) — validation of a screening instrument for use in medical settings. J Stud Alcohol 56:423-432

33. (2002) The alcohol use disorders identification test, pp 1-41

34. Cao W, Fang Z, Hou G et al (2020) The psychological impact of the COVID-19 epidemic on college students in China. Psychiatry Res 287:112934. https://doi.org/10.1016/j.psych res.2020.112934

35. Woodgate RL, Tailor K, Tennent P et al (2020) The experience of the self in Canadian youth living with anxiety: a qualitative study. PLoS ONE 15:e0228193. https://doi.org/10.1371/journ al.pone.0228193

36. Gentili D, Bardin A, Ros E et al (2020) Impact of communication measures implemented during a school tuberculosis outbreak on risk perception among parents and school staff, Italy, 2019. Int J Environ Res Public Health. https://doi.org/10.3390/ijerph1703 0911

37. Schechter DS, Willheim E (2009) Disturbances of attachment and parental psychopathology in early childhood. Child Adolesc Psychiatr Clin N Am 18:665-686. https://doi.org/10.1016/j. chc.2009.03.001

38. Pelham WE, Lang AR (1999) Can your children drive you to drink? Stress and parenting in adults interacting with children with ADHD. Alcohol Res Health 23:292-298

39. Yousefia S, Far AS, Abdolahian E (2011) Parenting stress and parenting styles in mothers of ADHD with mothers of normal children. Proc Social Behav Sci 30:1666-1671. https://doi. org/10.1016/j.sbspro.2011.10.323

40. Riley AW, Valdez CR, Barrueco S et al (2008) Development of a family-based program to reduce risk and promote resilience among families affected by maternal depression: theoretical basis and program description. Clin Child Fam Psychol Rev 11:12-29. https://doi.org/10.1007/s10567-008-0030-3

41. Bosanac P, Buist A, Burrows G (2003) Motherhood and schizophrenic illnesses: a review of the literature. Aust N Z J Psychiatry 37:24-30. https://doi.org/10.1046/j.1440-1614.2003.01104.x

42. Rasic D, Hajek T, Alda M, Uher R (2014) Risk of mental illness in offspring of parents with schizophrenia, bipolar disorder, and major depressive disorder: a meta-analysis of family high-risk studies. Schizophr Bull 40:28-38. https://doi.org/10.1093/schbu $1 / \mathrm{sbt} 114$

43. Galéra C, Pingault J-B, Fombonne E et al (2013) Attention problems in childhood and adult substance use. J Pediatr 163:16771683.e1. https://doi.org/10.1016/j.jpeds.2013.07.008

44. Song Z, Xu Y, Bao L et al (2019) From SARS to MERS, thrusting coronaviruses into the spotlight. Viruses. https://doi.org/10.3390/ v11010059

45. Liu JJ, Bao Y, Huang X et al (2020) Mental health considerations for children quarantined because of COVID-19. Lancet 
Child Adolesc Health 4:347-349. https://doi.org/10.1016/S2352 -4642(20)30096-1

46. Catalano R, Goldman-Mellor S, Saxton K et al (2011) The health effects of economic decline. Annu Rev Public Health 32:431-450. https://doi.org/10.1146/annurev-publhealth-031210-101146

47. Golberstein E, Gonzales G, Meara E (2019) How do economic downturns affect the mental health of children? Evidence from the National Health Interview Survey. Health Econ 28:955-970. https://doi.org/10.1002/hec.3885

48. Alfano CA, Zakem AH, Costa NM et al (2009) Sleep problems and their relation to cognitive factors, anxiety, and depressive symptoms in children and adolescents. Depress Anxiety 26:503512. https://doi.org/10.1002/da.20443

49. Yurumez E, Kilic BG (2016) Relationship between sleep problems and quality of life in children With ADHD. J Atten Disord 20:34-40. https://doi.org/10.1177/1087054713479666

50. Maras D, Flament MF, Murray M et al (2015) Screen time is associated with depression and anxiety in Canadian youth. Prev Med 73:133-138. https://doi.org/10.1016/j.ypmed.2015.01.029

51. Nagata JM, Abdel Magid HS, Gabriel KP (2020) Screen time for children and adolescents during the COVID-19 pandemic. Obesity (Silver Spring). https://doi.org/10.1002/oby.22917

52. Lissak G (2018) Adverse physiological and psychological effects of screen time on children and adolescents: literature review and case study. Environ Res 164:149-157. https://doi.org/10.1016/j. envres.2018.01.015

53. Király O, Potenza MN, Stein DJ et al (2020) Preventing problematic internet use during the COVID-19 pandemic: consensus guidance. Compr Psychiatry 100:152180. https://doi.org/10.1016/j. comppsych.2020.152180

54. Bjelland M, Soenens B, Bere E et al (2015) Associations between parental rules, style of communication and children's screen time. BMC Public Health. https://doi.org/10.1186/s12889-015-2337-6

55. Orben A (2020) Teenagers, screens and social media: a narrative review of reviews and key studies. Soc Psychiatry Psychiatr
Epidemiol 55:407-414. https://doi.org/10.1007/s00127-01901825-4

56. Neugebauer R, $\mathrm{Ng} \mathrm{S} \mathrm{(1990)} \mathrm{Differential} \mathrm{recall} \mathrm{as} \mathrm{a} \mathrm{source} \mathrm{of} \mathrm{bias}$ in epidemiologic research. J Clin Epidemiol 43:1337-1341

57. Mathai J, Anderson P, Bourne A (2004) Comparing psychiatric diagnoses generated by the strengths and difficulties questionnaire with diagnoses made by clinicians. Aust N Z J Psychiatry 38:639-643. https://doi.org/10.1080/j.1440-1614.2004.01428.x

58. Costello EJ, Foley DL, Angold A (2006) 10-year research update review: the epidemiology of child and adolescent psychiatric disorders: II. Developmental epidemiology. J Am Acad Child Adolesc Psychiatry 45:8-25. https://doi.org/10.1097/01.chi.00001 84929.41423.c0

59. Goodman R, Ford T, Simmons H et al (2000) Using the strengths and difficulties questionnaire (SDQ) to screen for child psychiatric disorders in a community sample. Br J Psychiatry 177:534-539. https://doi.org/10.1192/bjp.177.6.534

60. Duffy KA, McLaughlin KA, Green PA (2018) Early life adversity and health-risk behaviors: proposed psychological and neural mechanisms. Ann N Y Acad Sci 1428:151-169. https://doi. org/10.1111/nyas. 13928

61. Wade M, Prime H, Browne DT (2020) Why we need longitudinal mental health research with children and youth during (and after) the COVID-19 pandemic. Psychiatry Res 290:113143. https://doi. org/10.1016/j.psychres.2020.113143

62. Aljandaleh H, Bolze C, El-Khoury Lesueur F et al (2020) Factors associated with electronic cigarette use among young adults: the French "Trajectoires Epidé Miologiques en Population" (TEMPO) cohort study. Subst Use Misuse 55:964-972. https:// doi.org/10.1080/10826084.2020.1717534

63. Dalton L, Rapa E, Stein A (2020) Protecting the psychological health of children through effective communication about COVID-19. Lancet Child Adolesc Health 4:346-347. https://doi. org/10.1016/S2352-4642(20)30097-3 